\title{
Narrativas digitais no jornalismo: a interatividade encenada ${ }^{1}$
}

\author{
Ana Teresa Peixinho ${ }^{2}$ \\ Inês Fonseca Marques ${ }^{3}$
}

Resumo: Desde o advento da WEB2.0, o Jornalismo tem sofrido profundas alterações a vários níveis. Nesta comunicação, as autoras propõem-se focar a atenção nas mudanças retórico-textuais, patentes no aparecimento de novos suportes que têm permitido novos modelos de texto e novas formas de reportar. Com base numa análise de caso, que tem como corpus um conjunto de cinco reportagens interativas, publicadas entre abril e setembro de 2015, e anunciadas pela SIC como inovadoras, pretende-se problematizar as transformações narrativas no Jornalismo, decorrentes do advento da hipertextualidade digital. Se é já sabido, como bem o tentou demonstrar João Canavilhas há uma década, que a tradicional superestrutura da notícia - a pirâmide invertida - foi progressivamente substituída no jornalismo online pela "pirâmide deitada" (CANAVILHAS, 2006 e 2007); se os estudos narrativos têm admitido, nos últimos anos, a necessidade de uma reconfiguração dos seus aparelhos analíticos e teóricos, em função da produção e consumo de narrativas hipertextuais (LITS, 2014; RYAN, 2001); se, como certos autores revelam, o jornalismo tem sido preenchido pela atividade do storytelling digital (ALEXANDER, 2011; RYAN, 2006) cremos, apesar de tudo, não ter sido ainda claramente demonstrado em que medida as narrativas jornalísticas, de facto, se alteraram. Tentar-se-á, por agora, através do estudo de caso, perceber em que medida a interatividade anunciada com entusiasmo pela SIC se concretiza nessas reportagens. Para o efeito, parte-se do conceito de interatividade, como reconhecida propriedade hipertextual, para questionar a sua prática nas reportagens do webjornalismo.

Palavras-chave: hipertexto - multimédia - transmedialidade - narrativa - reportagem - interatividade.

Abstract: Since the advent of WEB2.0, journalism has undergone profound changes at all levels. In this paper, the authors propose to focus attention on rhetorical-textual changes, patents in the appearance of new media that have allowed new text models and new ways of reporting.

Based on a case study, whose corpus is a set of five interactive reports published between April and September 2015 and announced by the SIC as innovative, it is intended to question the narrative transformations in Journalism, due to the advent of digital hypertextuality.

If it is already known, the traditional superstructure of news - the inverted pyramid - was gradually replaced in online journalism by "pyramid lying" (Canavilhas, 2006 and 2007); if the narrative studies have admitted, in recent years, the need for a reconfiguration of their analytical and theoretical devices, depending on the production and consumption of hypertextual narratives (Lits, 2014; Ryan, 2001); if, as some authors reveal, journalism has been filled by the activity of digital storytelling (Alexander, 2011; Ryan, 2006) we believe, though, that it has still not been clearly demonstrated to what extent the journalistic narratives in fact have changed. We will try, for now, through the case study, to realize the extent to which interactivity is realized in these reports. To achieve this goal, we part from the concept of interactivity, as a hipertextual property, to question their practice in web journalism.

Key-words: hipertexto - multimídia - transmedia - narrative - report - interactivity.

${ }^{1}$ Este texto resulta de uma comunicação apresentada à 9. ${ }^{a}$ SOPCOM, que foi organizada na Universidade de Coimbra, em novembro de 2015.

${ }^{2}$ Portugal, FLUC / CEIS20. E-mail: apeixinho71@gmail.com.

${ }^{3}$ Portugal, Mestranda FLUC. E-mail: inesmatiasmarques@gmail.com. 


\title{
1. O objeto: do anúncio de uma reportagem digital
}

No dia 2 de abril deste ano (2015), a SIC publica aquela que é considerada a primeira reportagem interativa do jornalismo português: "Somos o que comemos" é o título da peça, da autoria da jornalista Miriam Alves, apoiada por uma equipa de mais dez profissionais, todos eles técnicos especializados tanto da televisão como do digital ${ }^{4}$ :

\begin{abstract}
Com a Grande Reportagem SIC estreamos um formato interativo onde pode encontrar mais conteúdos. Guiados pela pediatra Júlia Galhardo mostramos-lhe, por exemplo, como preparar pequenos almoços equilibrados ou como convencer crianças e adolescentes a comer peixe e legumes. Com o contributo de alguns dos maiores especialistas de cada área, pode aprofundar questões como o papel da alimentação na prevenção do cancro desde a infância ou as dependências alimentares. Textos, vídeos, entrevistas e gráficos que poderá explorar, ao seu ritmo. O próximo conteúdo interativo vai acontecer aos 4 minutos e 29 segundos ${ }^{5}$.
\end{abstract}

Explorando as potencialidades do digital, aquilo que se anuncia e promete é um modelo inovador e uma nova forma de concretizar um dos géneros de excelência do jornalismo - a reportagem -, sublinhando aquela que parece ser uma das grandes revoluções da comunicação do século XXI: a interatividade.

De facto, desde o advento da WEB2.0, o Jornalismo tem sofrido profundas alterações a vários níveis: económicas - já que um novo modelo de negócio adaptado ao online ainda não está perfeitamente definido; profissionais - pois o jornalista perdeu o monopólio da disseminação da informação num espaço público mais lato e cada vez mais difuso e caótico, amplamente disperso pelas redes sociais; e retórico-textuais - patentes no aparecimento de novos suportes que têm permitido novos modelos textuais e novas formas de reportar.

Tenta-se, por ora, problematizar as transformações narrativas no Jornalismo, decorrentes do advento da hipertextualidade digital, sem, no entanto, nunca perder de vista que as três arestas acima referidas se implicam e estabelecem interrelações dicotómicas. Se é já sabido, como bem o tentou demonstrar João Canavilhas há uma década, que a tradicional superestrutura da notícia - a pirâmide invertida - foi progressivamente substituída no

${ }^{4}$ Cf.Ficha Técnica: http://sicnoticias.sapo.pt/programas/2015-04-02-Ficha-tecnica-Somos-o-que-comemos [última consulta em 28/07/2015]

${ }^{5}$ Esta descrição é o primeiro conteúdo que abre a reportagem digital. 
jornalismo online pela "pirâmide deitada" (CANAVILHAS, 2006 e 2007); se os estudos narrativos têm admitido, nos últimos anos, a necessidade de uma reconfiguração dos seus aparelhos analíticos e teóricos, em função da produção e consumo de narrativas digitais (LITS, 2014; RYAN, 2001); se, como certos autores revelam, o jornalismo tem sido preenchido pela atividade do storytelling digital (ALEXANDER, 2011; RYAN, 2006), parece, apesar de tudo, não ter sido ainda claramente demonstrado em que medida as narrativas jornalísticas, de facto, se alteraram. $\mathrm{Na}$ verdade, cada um dos aspetos acabados de referir foram, a seu tempo, importantes contributos para a perceção do jornalismo na web, mostrando as diversas inovações, quer textuais e discursivas, quer comunicacionais e mesmo profissionais. A leitura que Canavilhas propôs veio mostrar que a superestrutura da pirâmide deitada permite explorar uma das mais profícuas potencialidades do wejornalismo, "a adoção de uma arquitetura noticiosa aberta e de livre navegação" (Canavihas, 2006: 7), que confere autonomia e poder ao leitor / usuário para decidir do grau de imersão na informação ${ }^{6}$. Também Marc Lits, em artigo recente, defende que o aparelho analítico dos estudos narrativos tem forçosamente de se adaptar e evoluir, no sentido de conseguir abranger as transformações que as tecnologias (sempre em acelerada superação) têm trazido para o universo das narrativas mediáticas:

\begin{abstract}
Atualmente e numa altura em que as novas tecnologias modificaram os modos de construção da narrativa e as práticas das redações, em que os utilizadores são também co-construtores da informação que leem e criticam, torna-se necessário rediscutir a pertinência da própria noção de narrativa. Esta surge mais fragmentada, aberta a reescritas, a formas polifónicas que carecem da criação de uma hipernarratologia" (LITS, 2015: 13).
\end{abstract}

No entanto, também refere um estudo interessante, em que se analisam comparativamente peças jornalísticas tradicionais, ou seja, de jornais impressos, e peças do jornalismo online. As conclusões a que este estudo chega, sublinhadas pelo professor belga, contrariam a noção generalizada segundo a qual a escrita e a textualidade jornalísticas se alteraram totalmente com a entrada no online: os resultados apontam precisamente para um certo conservadorismo e manutenção de técnicas de redação tradicionais (LITS, 2015).

\footnotetext{
${ }^{6}$ Embora citemos aqui o artigo inaugural desta teoria, chamamos a atenção para ensaio posterior, em que o autor, e bem, relativiza a exequibilidade deste modelo, já que dentro demonstra como os usuários preferem a integração dos conteúdos no lugar da dispersão piramidal (Canavilhas, 2014).
} 
Esta questão converge numa outra, bem mais complexa e antiga, que se prende com o facto de se perceber se o medium influencia a narrativa ou se, pelo contrário, esta é totalmente independente daquele. A obra de 2011 de Bryan Alexander faz a apologia entusiástica da atividade do storytelling digital e das novas arquiteturas narrativas. Contudo por explicar fica, na verdade, o que de facto muda na essencialidade da narrativa. David Herman (2004: 50 e ss), inspirado na leitura de Monika Fludernik, que lhe permitirá preconizar uma narratologia transmedial fundamentalmente transdisciplinar, postula que essa relação - entre medium e narrativa - depende inevitavelmente das propriedades daquele, bem como dos formatos de narrativa.

Pretende-se, agora, com base na análise de um conjunto de 5 reportagens interativas, problematizar o conceito de interatividade inerente ao jornalismo na web, que tem sido uma bandeira das novas narrativas mediáticas. Até que ponto essa interatividade se concretiza, dando ao público - leitor / espectador - o poder de se assumir como coautor dos textos? De que se fala quando se anuncia a produção da primeira reportagem interativa portuguesa? Para tentar gizar algumas respostas a estas questões, parte-se da análise a um conjunto de reportagens, vendidas ao espectador / usuário como inovadoras reportagens interativas da TV portuguesa.

\section{Análise de Reportagens}

O nosso corpus é constituído pelas cinco reportagens da SIC, publicadas na SIC Notícias online como reportagens interativas, ou seja, com "conteúdos extra", entre abril data em que o formato é estreado - e julho de 2015. Foram elas: i) "Somos o que comemos" (abril), um trabalho que mostra a importância de uma alimentação saudável; ii) "Brasil Global" (maio), sobre a TV Globo, uma rede de emissoras televisivas brasileira, e o seu impacto como elemento unificador do país; iii) "No tempo das Cesarianas" (junho), acerca a taxa de cesarianas em Portugal e as suas implicações; iv) "Laboratório Antártida" (junho), cujo tema é a investigação científica realizada naquele continente; v) e, finalmente, "Os

\footnotetext{
${ }^{7}$ Designação utilizada pela própria estação televisiva, quando anuncia a emissão da reportagem "Somos o que comemos": "Para ver no Jornal da Noite, esta quinta-feira - e em versão interativa, com conteúdos extra exclusivos [...]". In: http://sicnoticias.sapo.pt/programas/reportagemsic/2015-03-27-Somos-o-que-comemos
} 
Tratadores" (julho), cujo assunto é a domesticação de animais para efeitos terapêuticos. Pelo exposto, se pode verificar que a amplitude temática é grande, embora todas essas reportagens tenham como denominador comum o tratamento de temáticas não efémeras, cuja atualidade não se limita ao imediato. Facto a que não são alheios quer o género, reportagem, quer o período do ano em que foram divulgadas: antes e durante o verão, época em que, como é sabido, a lógica dos critérios de noticiabilidade se altera, fruto das próprias alterações à agenda política e social do país.

Para além de uma análise semiótica, em que identificamos os tipos de códigos utilizados em cada 'conteúdo-extra' presente nas reportagens, o enfoque na interatividade que pretendíamos imprimir nesta análise exigiu a visualização/utilização das reportagens e o levantamento e confirmação de hipóteses. Deste modo, quando do visionamento da primeira reportagem, "Somos o que comemos", tentámos perceber como é que ela estava estruturada e se, de facto, correspondia à prometida interatividade que fora anunciada. Após a compreensão do seu funcionamento, procedemos à visualização das outras quatro reportagens, verificando se as hipóteses levantadas para a primeira reportagem se confirmavam ou não. Foi, então, através deste método hipotético-indutivo que chegámos a resultados que se aplicam às cinco reportagens analisadas.

No que à análise semiótica diz respeito, procurámos, num primeiro momento, analisar cada conteúdo, de acordo com as seguintes categorias:

Tabela 1: Categorias de análise

\begin{tabular}{|l|l|}
\hline 1 & Texto (existência ou não) \\
\hline 2 & Número de parágrafos de texto \\
\hline 3 & Autoria do texto (SIC/ Outro) \\
\hline 4 & Vídeo (existência ou não) \\
\hline 5 & Duração do clip de vídeo \\
\hline 6 & $\begin{array}{l}\text { Tipo de vídeo (entrevista/vivo; } \\
\text { gravação in loco; música; peça } \\
\text { jornalística/televisiva; animação) }\end{array}$ \\
\hline 7 & Imagens (existência ou não) \\
\hline 8 & Número de imagens \\
\hline 9 & $\begin{array}{l}\text { Tipo de imagens (fotografia; } \\
\text { infografia; documento digitalizado) }\end{array}$ \\
\hline 10 & Links (existência ou não) \\
\hline 11 & Número de links \\
\hline
\end{tabular}


Após a análise de cada conteúdo, procedeu-se à quantificação dos elementos presentes em cada uma das peças. Os resultados são os que se apresentam na tabela 2:

Tabela 2: Elementos presentes nos conteúdos extra

\begin{tabular}{|c|c|c|c|c|c|c|c|}
\hline Reportagem & $\begin{array}{c}\text { N.o de } \\
\text { conteúdos } \\
\text { extra }\end{array}$ & $\begin{array}{c}\mathrm{N} .^{\circ} \text { de } \\
\text { parágrafos } \\
\text { de texto }\end{array}$ & $\begin{array}{c}\mathrm{N} .{ }^{\circ} \mathrm{de} \\
\text { imagens }\end{array}$ & $\begin{array}{l}\text { N. } .^{\circ} \text { de } \\
\text { clips de } \\
\text { vídeo }\end{array}$ & $\begin{array}{c}\text { Duração } \\
\text { total do } \\
\text { vídeo }\end{array}$ & $\begin{array}{l}\mathrm{N}^{\circ} \mathrm{de} \\
\text { links } \\
\text { internos } \\
\text { (SIC) }\end{array}$ & $\begin{array}{c}\text { N. } .^{\circ} \text { de } \\
\text { links } \\
\text { externos } \\
\text { (outros) }\end{array}$ \\
\hline $\begin{array}{l}\text { "Somos o } \\
\text { que } \\
\text { comemos" }\end{array}$ & 15 & 143 & 34 & 4 & $\begin{array}{c}22 \mathrm{~m} 48 \\
\mathrm{~s}\end{array}$ & 0 & 13 \\
\hline $\begin{array}{l}\text { "Brasil } \\
\text { Global" }\end{array}$ & 14 & 19 & 24 & 8 & $\begin{array}{c}16 \mathrm{~m} 19 \\
\mathrm{~s}\end{array}$ & 0 & 3 \\
\hline $\begin{array}{c}\text { "No Tempo } \\
\text { das } \\
\text { Cesarianas" }\end{array}$ & 8 & 41 & 1 & 2 & $\begin{array}{c}07 \mathrm{~m} 35 \\
\mathrm{~s}\end{array}$ & 0 & 7 \\
\hline $\begin{array}{l}\text { "Laboratóri } \\
\text { o } \\
\text { Antártida" }\end{array}$ & 15 & 41 & 48 & 5 & $\begin{array}{c}03 \mathrm{~m} 31 \\
\mathrm{~s}\end{array}$ & 2 & 5 \\
\hline $\begin{array}{c}\text { "Os } \\
\text { Tratadores" }\end{array}$ & 11 & 145 & 10 & 3 & $\begin{array}{c}17 \mathrm{~m} 34 \\
\mathrm{~s} \\
\end{array}$ & 0 & 2 \\
\hline
\end{tabular}

O rótulo escolhido pela SIC para anunciar estas cinco reportagens - como produtos interativos - resulta claramente da junção destes 'conteúdos-extra' a algumas das reportagens que passam na televisão em formato tradicional, já que é este fator o único que as diferencia. 
Vejamos, então, como funcionam. As chamadas reportagens interativas estão alojadas em links específicos: em vez de a reportagem começar a ser reproduzida no player do site da SIC Notícias, no canto superior esquerdo, somos encaminhados para uma página onde aparece, em janela inteira, uma imagem de fundo, o título da reportagem, o lead (nem sempre presente) e o símbolo play (Fig. 1). Ao fundo dessa janela surge uma barra onde constam os logótipos dos canais (SIC e SIC Notícias), o ano da reportagem - a data específica só é possível saber-se através do endereço -, o logótipo da "Grande Reportagem", o título, os logótipos das redes sociais (email, Facebook, Twitter, Pinterest, Google+) para partilha e o botão para aceder à ficha técnica.

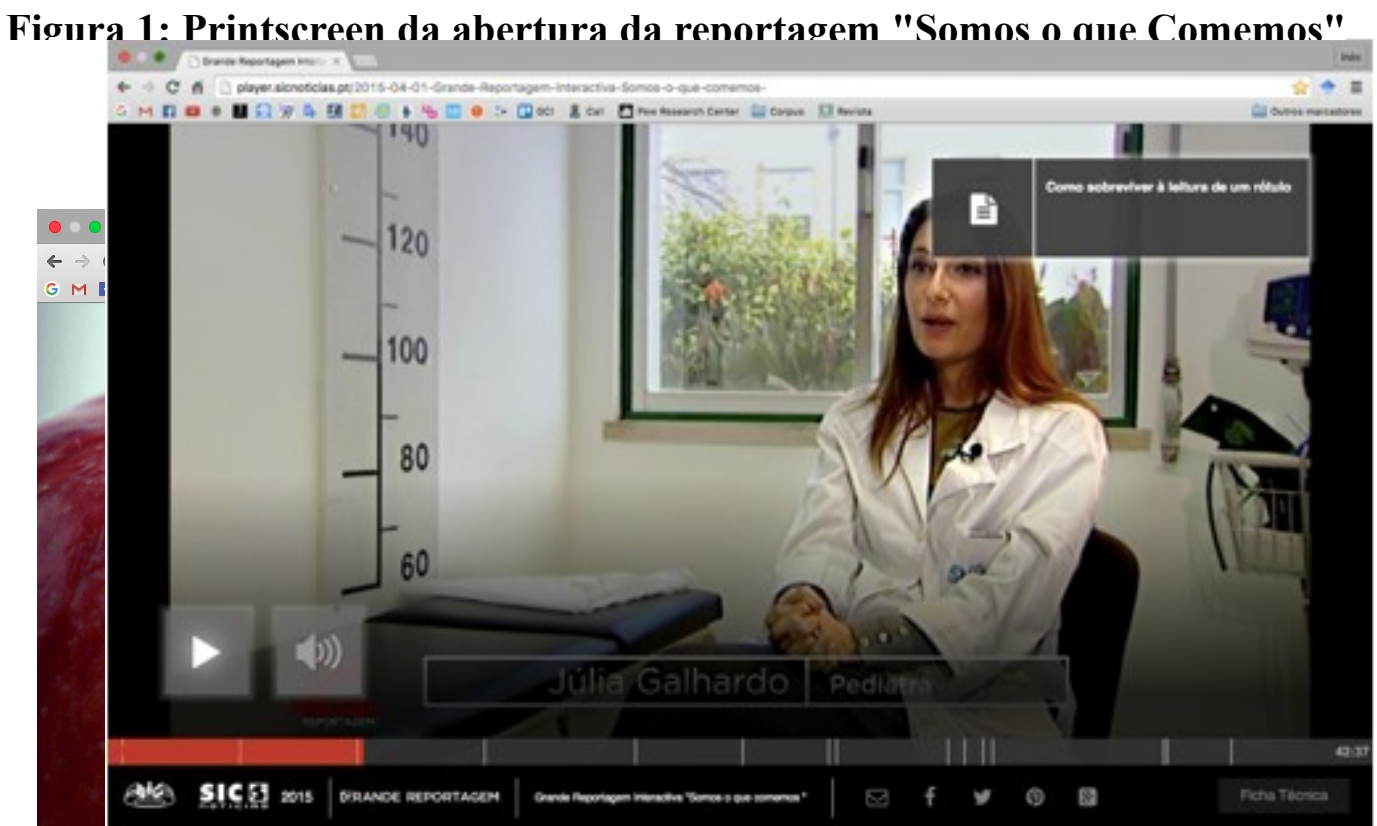

Figura 2: Exemplo de lançamento de 'conteúdo-extra'

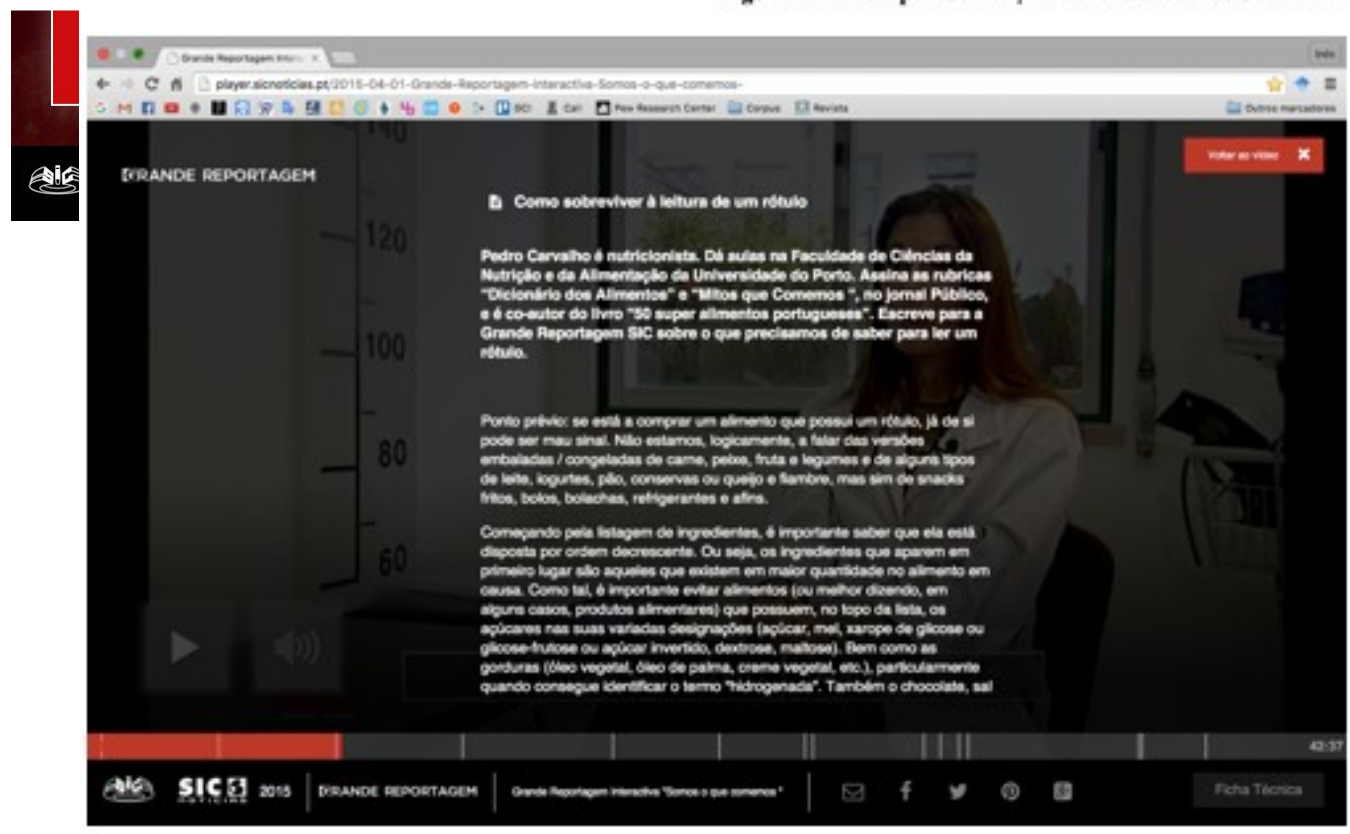


reprodução, uma linha de tempo é apresentada ao fundo. É nela que os 'conteúdos-extra' estão sinalizados por estreitas barras verticais que a atravessam (Fig. 2). Deste modo, avançando manualmente na linha, é possível ir diretamente para esses conteúdos. Contudo, caso não se avance manualmente e se opte por visualizar a reportagem completa, quando se chega ao momento em que essas barras aparecem, surgem duas caixas cinzentas no canto superior direito: da da direita consta o título do 'conteúdo-extra', enquanto a da esquerda contém um ícone que simboliza o tipo de conteúdo (o símbolo play sinaliza um vídeo; duas folhas de papel dobradas no canto, uma galeria de fotos; três linhas paralelas, uma imagem; e uma folha de papel com três linhas, um texto). Ao clicar numa dessas caixas, a reportagem é colocada em pausa e o ecrã é ocupado pelo 'conteúdo-extra (Fig. 3). Ao fechar a caixa dos conteúdos, a reprodução da reportagem é automaticamente retomada.

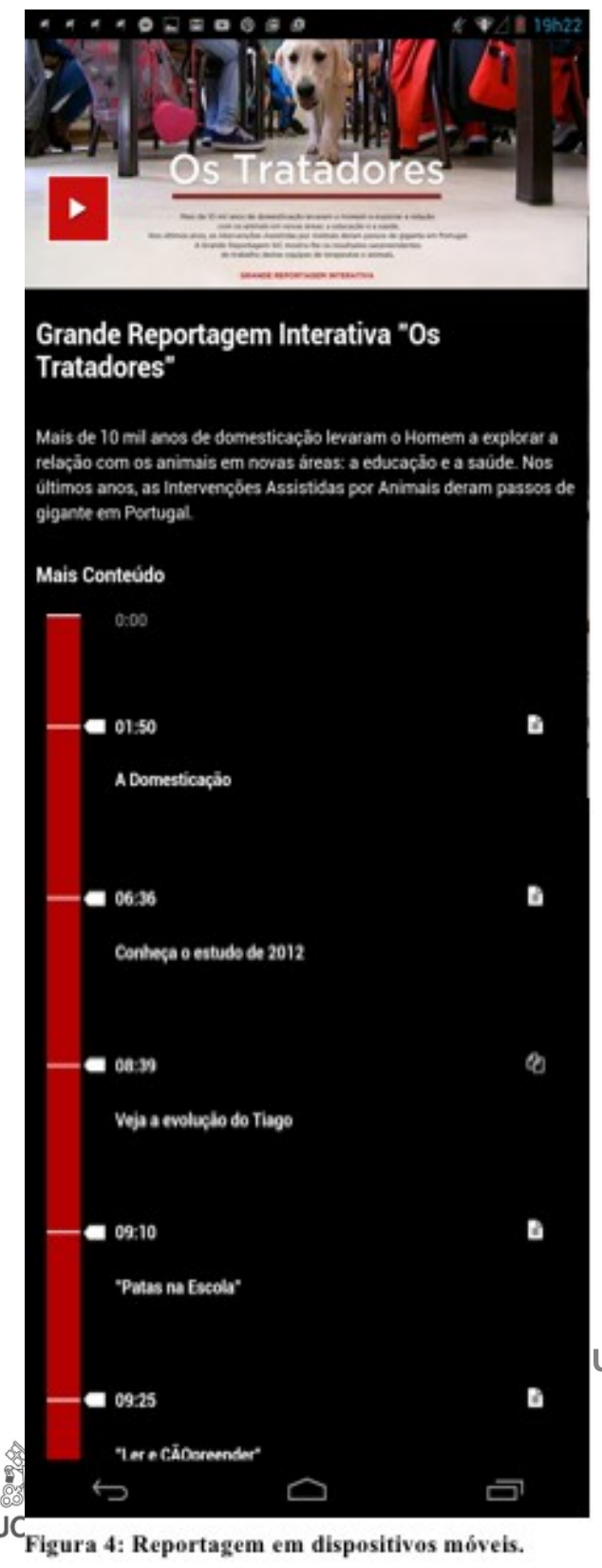

A nosso ver, este funcionamento tem um inconveniente: acontece algumas vezes que os 'conteúdos-extra' surgem a meio de um vivo ou mesmo de um off, não Quanto ao conteúdo dos elementos extra, importa referir que o uso de hiperligações é bastante recorrente, tanto em conteúdos da autoria da própria SIC, como em textos de outros autores. Quando se trata de galerias, cada imagem é representada por um círculo e há setas para avançar ou recuar, embora seja possível aceder às imagens pela ordem que se desejar, bastando para isso clicar em cada círculo.

Se, hoje em dia, é dado adquirido que o acesso à internet não se faz exclusivamente através do computador, estando, inclusivamente, a crescer o número o número de 
acessos por dispositivos móveis ${ }^{8}$, importa também perceber o funcionamento das reportagens interativas da SIC em telemóveis e tablets. Neste caso, não há qualquer interferência dos 'conteúdos-extra' no vídeo: este aparece no topo do ecrã e, abaixo dele, existe uma barra vermelha vertical, precedida do título "Mais conteúdo", onde aqueles são disponibilizados (Fig. 4).

Similarmente ao que acontece nos computadores, existe uma pequena barra que atravessa a linha de tempo, sinalizando os 'conteúdos-extra'. Paralelamente, somos informados sobre a que momento da reportagem esse conteúdo se refere - minutos e segundos - e, abaixo, surge o título e o símbolo que assinala o tipo de conteúdo. Este tipo de configuração faz, portanto, com que, em dispositivos móveis, não haja qualquer cruzamento entre a reportagem e os outros conteúdos, o que contraria a ideia expressa por Guerrero (apud Videla Rodriguéz et alii, 2013: 220-221), segundo a qual o potencial dos telemóveis e dos tablets, enquanto "novos ecrãs de televisão", reside no facto de enriquecerem a experiência do espetador, além de permitirem uma receção mais alargada dos conteúdos. Ora, se podemos admitir que, mesmo não concretizando totalmente a promessa de interatividade, as reportagens da SIC Notícias Online têm algum valor acrescentado em relação à versão televisiva, não nos parece que o mesmo aconteça nos dispositivos móveis, já que o vídeo e os 'conteúdos-extra' surgem de forma completamente distinta.

Assim, é o acesso a estes 'conteúdos-extra' o único aspeto que diferencia a reportagem que é colocada na WEB daquela que passa na televisão. Mas será o suficiente para se dizer que estamos perante reportagens interativas?

\section{A interatividade encenada}

É certo que muito do que se tem escrito sobre o panorama dos media do século XXI considera, de modo entusiástico, a interatividade como uma das grandes revoluções na forma de fazer e pensar o jornalismo, a 'grande promessa' ${ }^{9}$ deste novo jornalismo online. Em 2001, ainda antes do advento da WEB 2.0, João Canavilhas escrevia: “A máxima nós escrevemos,

\footnotetext{
${ }^{8}$ Um estudo do Pew Research Center, de 2008, prevê que, em 2020, "o telemóvel será a principal ferramenta de conexão à internet para a maior parte das pessoas no mundo". Outro estudo do mesmo centro, datado deste ano, revela que $91 \%$ dos jovens acede à internet através de dispositivos móveis.

${ }^{9}$ Paráfrase do título de um artigo, publicado em 2001, por Elisabete Barbosa (Barbosa, 2001). 
vocês leem pertence ao passado" (Canavilhas, 2001). E, um ano antes, Gerd Kopper definia a interatividade como

uma das características mais proeminentes que distingue os media online dos media tradicionais. A tecnologia da Internet permite uma verdadeira comunicação bidirecional, utilizando o correio eletrónico e os fóruns de discussão como meios de interligação na comunicação de massas ou na comunicação interpessoal em pequena escala (Kopper, 2000: 500).

Quinze anos passados sobre estas análises, a pergunta que se impõe é a seguinte: será a interatividade, perspetivada por estes investigadores, uma realidade concreta no jornalismo? Existirá verdadeiramente uma possibilidade de intercomunicação entre jornalistas e leitores? É muito curioso o exercício de comparação entre aquilo que, nesse início de milénio, era projetado, e aquilo que na verdade o tempo se encarregou de demonstrar. Parece-nos que a resposta a estas questões necessita que se defina previamente de modo rigoroso o que se entende por interatividade. Recorde-se que, em 1999, já Tanjev Schultz chamava a atenção para o facto de ser importante distinguir a reação dos leitores / usuários da interatividade, que deve pressupor a existência de uma permuta continuada de mensagens:

Interactivity requires a thread of messages, i.e. a chain of interrelated messages. The degree to which communication transcends reaction is key. In one-way communication, one source sets the agenda, receiving no or (at most) indirect feedback. In two-way and reactive communication, both sides "send" messages (Schultz, 1999).

No entanto, parece-nos que tem existido, quer por parte de alguns académicos, quer sobretudo de alguns sites e empresas de media, um abuso na utilização do termo. A abordagem ao conceito tem sido de certa forma desvirtuada, na medida em que se considera que a possibilidade de o usuário / leitor, através de um simples click, poder aceder aos conteúdos que lhe interessam, como um exemplo de interatividade. Aceitando como válida, mas parcelar, a definição de Manuel de la Fuente, segundo a qual a interatividade é "um termo que se refere especificamente à relação entre jornalista - conteúdo - audiência, referindo-se a um tema relativamente novo na literatura sobre media de massas eletrónicos" (Fuente et alii, 2015: 211), parece-nos que nem todos os fenómenos jornalísticos que hoje usam a bandeira da interatividade podem ser considerados verdadeiramente interativos. Quase nos apetece citar o 
sugestivo título de um artigo de Dominique Paul: "Interactive or Hyperactive? Newspapers and other sites abuse the term."

Quando, no início da década de 70 do século passado, Roland Barthes projetou seu conceito de textualidade ideal, descreve-a da seguinte forma:

\begin{abstract}
Neste texto ideal, abundam as redes que atuam entre si sem que nenhuma possa impor-se às demais; este texto é uma galáxia de significantes e não uma estrutura de significados; não tem princípio, mas antes diversas vias de acesso, sem que nenhuma delas possa qualificar-se de principal; os códigos que mobiliza estendem-se até onde a vista possa alcançar; são indetermináveis...; os sistemas de significados podem impor-se a este texto absolutamente plural, mas o seu número nunca é limitado, já que se baseia na pluralidade da linguagem (Barthes, 1970: 11-12).
\end{abstract}

O ideal barthesiano de texto - organização não hierárquica em rede, em que a rigidez estrutural dos significados é substituída por uma constelação significante, na qual o texto esbate a nitidez dos seus limites, convidando a uma multiplicidade de leituras e de caminhos possíveis - é hoje uma realidade, a realidade da hipertextualidade digital ${ }^{10}$, que, durante a primeira década do século XXI, se transformou essencialmente devido a três tendências da web: o aparecimento e multiplicação de novas plataformas, a valorização de microconteúdos e aquilo a que Bryan Alexander chama de nova "arquitetura social" (Alexander, 2011: 29). Para este autor, as peças de microconteúdo, além de serem de produção mais simples, não exigindo os conhecimentos técnicos que a primeira geração da WEB exigia, possibilitam a reciclagem, podendo ser reutilizados nas diversas plataformas. A nova arquitetura social, ela própria em contínua evolução, permite, de acordo com o autor, a ligação entre os usuários, com níveis de intensidade variáveis de acordo com a plataforma utilizada (por exemplo, a diferença entre o MySpace e o Facebook).

$\mathrm{Na}$ verdade, de todos os aspetos revolucionados na escrita e na leitura do texto com o advento e desenvolvimento tecnológico, aquele que nos parece de facto mais marcante é a interatividade: no hipertexto, o leitor (latu sensu) adquire uma liberdade e uma autonomia que a textualidade tradicional não the facultava. Cabe-lhe a ele estabelecer os seus percursos de leitura, reinventar os inícios e os finais dos textos, assumindo-se quase como um coautor, no sentido em que é capaz de construir, na sua errância, um percurso único e original, diferente de qualquer outro, conferindo, desse modo, novos sentidos ao objeto percecionado. Esta é a

\footnotetext{
${ }^{10}$ Sobre hipertexto vejam-se as seguintes obras: Furtado, 2010; Landow, 1995; Virgil, 2007. 
definição teórica de hipertexto que encontramos em autores como Landow (1995) ou Afonso Furtado (2000).

Este empoderamento do leitor se, no domínio da ficção, pode representar uma maisvalia e um desafio artístico para o criador, aliás muito explorado na literatura digital, no âmbito da textualidade jornalística - à qual aqui nos cingiremos - representa um risco e uma alteração radical dos tradicionais princípios da profissão, de que o chamado jornalismo do cidadão pode ser um exemplo ${ }^{11}$. Num interessante ensaio sobre os media digitais e a expansão da textualidade, Pedro Reis, a respeito das potencialidades da webliteratura, comenta:

\begin{abstract}
A mobilidade, a temporalidade, a topologia e a multiplicidade estão naturalmente ligadas à interatividade, isto é, à possibilidade de um texto ser sensível às eventuais ações de um ou vários leitores, o que constituiu, a meu ver, uma das implicações mais determinantes, para a reconsideração do texto, já que interfere com uma tradição milenar que predispunha o leitor a fruir de uma obra sem intervir na sua materialidade (Reis, 2006: 6).
\end{abstract}

Contudo, parece-nos que, se a intervenção do leitor na literatura digital tem sido, de facto, uma marca clara de um novo processo de criação artística, revolucionando a prática e receção textuais, no caso do jornalismo, essa proatividade tem ficado aquém. $O$ facto de existirem diversos instrumentos tecnológicos à disposição dos leitores - chat, email, fóruns, redes sociais com linkagem nas páginas online dos meios de comunicação social - por si não nos parece ser suficiente para se afirmar que a interatividade é hoje uma realidade concreta do jornalismo.

É certo que estamos longe já da comunicação de massas, em que o leitor era um recetor de conteúdos, assumindo um papel passivo, com poucas hipóteses de interferência e restrita liberdade de escolha:

Así, en cuanto una de las características matriciales de la comunicación de masas es la uní-direccionalidad, la de la comunicación en red es la interactividad, palabra clave más penetrante del paisaje retórico creado en torno de los nuevos medios (Simões, 2012: 6)

\footnotetext{
${ }^{11}$ Comungamos de opinião similar à de Juan Luís Cebrián, quando afirma, a propósito do desenvolvimento do jornalismo cidadão, no atual cenário da web: "El periodismo ciudadano incide en cualquier caso, por propio derecho, en la capacidad productiva de los diarios que dedican importantes espacios de sus ediciones digitales a recoger y difundir esas experiencias. A cambio, padecemos una absoluta falta de rigor. Hay pocos reportajes yaún menos información que pase por controles rigurosos de verificación de los hechos o que estén sometidos al escrutinio editorial (Cebrián, 2015: 248).
} 
Também é certo que as reportagens digitais que acabámos de analisar nos mostram como o webjornalismo tem explorado algumas potencialidades tecnológicas, nomeadamente a multimedialidade e a hipertextualidade, oferecendo aos usuários a possibilidade de aprofundar aspetos diversos que funcionam como extensões da narrativa principal. Contudo, parece-nos francamente excessivo considerar que estas peças conferem ao leitor o poder de controlo e menos ainda a possibilidade de se situar num patamar comunicacional similar ao do emissor. Por outras palavras, cremos que a interatividade é sobretudo fruto de uma encenação, fazendo parte de uma estratégia de autopromoção dos órgãos de comunicação que a aclamam.

\section{Conclusões}

Essa interatividade funciona, de facto, como um estandarte do jornalismo digital, uma marca utilizada mais como estratégia promocional do que como estratégia de construção de conteúdos partilhada. A análise a que procedemos, embora com um corpus restrito ao universo do jornalismo nacional, é um bom exemplo disso. As reportagens, anunciadas publicamente como reportagens interativas, não o são verdadeiramente: em primeiro lugar, porque há um claro domínio da narrativa-mãe, garante da coesão do produto; em segundo lugar, porque as linkagens não permitem uma verdadeira permuta de papéis entre emissores e recetores, possibilitando, quando muito, que o recetor possa percorrer alguns atalhos, aprofundando assuntos que lhe interessem.

Se considerássemos, como o fazem, por exemplo, Kerenine Cunha e Paulo Mantello (2014: 59), que a possibilidade de os leitores "curtirem, compartilharem e comentarem" os conteúdos é um recurso efetivo da interatividade, poderíamos dizer que estamos perante reportagens interativas, já que os botões que permitem a partilha destes trabalhos jornalísticos nas redes sociais são uma presença constante durante a sua visualização. Contudo, não nos parece que, tanto esta possibilidade oferecida pela WEB, como outras ${ }^{12}$, possam concretizar uma verdadeira interatividade, tal como a definimos acima. É certo que as redes sociais dão

\footnotetext{
${ }^{12} \mathrm{Cf}$. as enunciadas por Rost (2014: 58) - "comentários abaixo das notícias, perfis em redes sociais abertas à participação de utilizadores, blogues de cidadãos/as, pesquisas, fóruns, entrevistas a personalidades com perguntas de utilizadores, publicação de endereços de correio eletrónico de jornalistas, ranking de notícias, chats, envio de notícias/fotografias/vídeos, sistemas de correção de notas, entre outros".
} 
ao espetador um poder de intervir no espaço público que nunca antes ele teve. Contudo, neste caso concreto, essa intervenção não tem qualquer impacto na narrativa.

Por outro lado, os 'conteúdos-extra', só por si, não permitem atingir o sentido global do tema que a reportagem pretende abordar: caso o leitor decida autonomamente seguir um desses percursos alternativos, pois a lógica hipertextual assim lho permite, é possível vir a conhecer temas, espaços e personagens, mas a falta de coesão entre os conteúdos, não lhe possibilitará perceber a sua relação. Ou seja, a construção da narrativa inicial, feita pelo jornalista, continua a ser a pedra de toque da reportagem. Por outro lado, o ideal barthesiano que há pouco citámos, segundo o qual no "texto ideal, abundam as redes que atuam entre si sem que nenhuma possa impor-se às demais" não se concretiza aqui: a reportagem tradicional impõe-se sempre perante os 'conteúdos-extra', como uma espécie de argumento, de nó górdio da sintaxe narrativa. Os desvios permitidos pelos links, que estão à disposição do leitor, constituem inquestionavelmente uma estratégia de customização de conteúdos, já que, enquanto a reportagem que passa na televisão é pensada para um espectador comum e construída de modo a que qualquer pessoa a possa entender, os 'conteúdos-extra' poderão ser pensados para um leitor mais sofisticado, com capacidade e interesse para ir mais além: aceder a artigos científicos, a informação institucional, a fontes, etc. Tanto assim é que o formato, lançado em abril, parece não ter tido o sucesso esperado, a avaliar pela sua descontinuidade ao fim de cinco peças apenas. Pode conjeturar-se que uma narrativa deste tipo ocupa um espaço editorial tipicamente estival, quer pela amplitude temporal quer pelo estilo dos temas tratados, o que, em nosso ver, confirma não existir ainda, no ecossistema mediático nacional, grande apetência por novidades deste género.

\section{BIBLIOGRAFIA}

ALEXANDER, B. (2011). The New Digital Storytelling. Creating Narratives with New Media. Oxford: Praeger.

BARBOSA, E. (2001). "Interactividade: A grande promessa do Jornalismo Online". In: www.bocc.ubi.pt (Consultado em agosto de 2015).

BARTHES, R. (1970). S/Z. Paris: Seuil. 
CANAVILHAS, J. (2014). "A reportagem paralaxe como marca de diferenciação da WEB". In: REQUEIJO REY, P.; GAONA PISONERO, C. (Eds.). Contenidos Innovadores en la Universidad Actual. Madrid: McGraw-Hill Education, pp. 119-129.

CANAVILHAS, J. (2010). “O novo ecossistema mediático". In: http://www.bocc.ubi.pt/pag/canavilhas-joao-o-novo-ecossistema- mediatico.pdf

CANAVILHAS, J. (2007). Webnoticia: popuesta de modelo periodístico para la WWW. Covilhã: Labcom.

CANAVILHAS, J. (2006). "Webjornalismo: da pirâmide invertida à pirâmide deitada"in http://bocc.ubi.pt/pag/canavilhas-joao-webjornalismo-piramide- invertida.pdf

CEBRIÁN, J. L. (2015). "Redes Sociales y Periodismo". In: PEIXINHO, A.T. et alii (Org.). 20 Anos de Jornalismo Contra a Indiferença. Coimbra: IUC, pp. 241-250.

CUNHA, Karenine e MANTELLO, Paulo (2014). "Era uma vez a notícia: Storytelling como técnica de redação de textos jornalísticos". Revista Comunicação Midiática (online), BAURU/SP, v. 9, n. 2. São Paulo: Universidade Estadual Paulista.

FURTADO, J. A. (2000). Os Livros e as Leituras - Novas Ecologias da Informação. Lisboa: Livros e Leituras, 2000.

HERMAN, David - "Toward a transmedial narratology". In: Ryan, Marie-Laure (Ed.) Narrative Across Media. The languages of storytelling. University of Nebraska, 2004, pp. 50 e ss.

KOPPER, G. Et al. (2000). "Online Journalism - a Reporto n Current and Continuing Research and Major Questions in the International Discussion”. In: Journalism Studies, vol. 1, n. ${ }^{\circ} 3$, pp. 4999-512.

LANDOW, G. (1995). Hipertexto. La convergencia de la teoría crítica contemporánea y la tecnología. Barcelona: Paidós.

LITS, M. (2015). "As investigações sobre a narrativa mediática e o futuro da imprensa". In: Mediapolis. Vol.1, Coimbra: IUC, pp. 13-27 https://digitalis.uc.pt/pt-pt/artigo/investiga $\% \mathrm{C} 3 \% \mathrm{~A} 7 \% \mathrm{C} 3 \% \mathrm{~B} 5$ es sobre narrativa medi $\% \mathrm{C} 3 \% \mathrm{~A} 1$ tica e o futuro da imprensa

REIS, P. (2006). "Media Digitais: novos terrenos para a expansão da textualidade". In: http://bdigital.ufp.pt/bitstream/10284/852/1/cibertxt1 43-52 reis.pdf (Consultado em agosto de 2015).

ROST, Alejandro (2014). "Interatividade: Definições, estudos e tendências". In: CANAVILHAS, João (org.). Webjornalismo: 7 caraterísticas que marcam a diferença.

RYAN, M-L. (2006). Avatars of the Story. Minnesota: University of Minnesota Press.

RYAN, M.-L. (2001). Narrative as virtual Reality. Immersion and Interactivity in Literature and Electronic Media. London: The Johns HopkinsUniversity Press. 
RYAN, M.-L. e THON, Jan-Noel (2014). Introduction. Storyworlds across Media. Toward a Media-Concious Narratology. Lincoln e Londres: University of Nebraska Press.

SCHULTZ, T. (1999). "Interactive Options in Online Journalism: A contente analysis of 100 U.S. Newspapers”. In: Journal of Computer Mediated Communication, Vol. 5, n. ${ }^{\circ} 1$. http://onlinelibrary.wiley.com/doi/10.1111/j.1083-6101.1999.tb00331.x/full (consultado em setembro de 2015).

SIMÕES, R. B.; PEIXINHO, A.T.; CAMPONEZ, C.C. (2012). "La nueva cultura de los públicos: las noticias de crimen y castigo y los comentarios de los lectores en el espacio digital". Comunicação apresentada ao Colóquio Cross Disciplinary International Conference, Madrid: Saint Louis University.

VIDELA RODRIGUÉZ, José J.; DÍAZ-GONZÁLEZ, María-Jesús; GARCÍA TORRE, Manuel (2013). "Contenidos periodísticos audiovisuales en aplicaciones móviles de televisión". In: CANAVILHAS, João (org.). Notícias e mobilidade. O jornalismo na era dos dispositivos móveis. Covilhã: Livros LabCom.

VIRGIL, J. (2007). “A Biblioteca de Babel: uma metáfora da sociedade da informação". In: Revista da Ciência da Informação. V. 8, n. ${ }^{\circ}$, agosto, 2007. Disponível em: http://www.dgz.org.br/ago07/Art.04.htm (Consultado em 8 de fevereiro de 2015). 